\section{Internationalizing the Curriculum and all Students' Learning}

\section{BetTy LeASK}

Betty Leask is Executive Director of Learning and Teaching at La Trobe University, Melbourne, Australia. She is editor in chief of the Journal of Studies in International Education. E-mail: B.Leask@latrobe.edu.au.

$\mathrm{R}$ ecently there has been a resurgence of interest in internationalization of the curriculum in theory and in practice. Essentially, this is because internationalization of the curriculum has the potential to connect broader institutional agendas focused on internationalization with student learning. All students will live in a globalized world, as professionals and citizens, and this is a common rationale for internationalization. Hence, university policy statements contain many well-intentioned, often bold, and certainly visionary statements focused on graduates with international and global perspectives, ready and able to make a positive difference in our increasingly interconnected yet divided world.

Many of these policy statements either explicitly or implicitly link the vision of internationally, interculturally, and globally competent graduates to all students. However, exactly how these statements are connected with student learning in the disciplines through internationalization of the curriculum is not clear. For example, in some universities the focus of internationalization of the curriculum is primarily on outbound student mobility which, for pragmatic reasons, involves a small percentage of students. In some universities the focus is on teaching in English but rarely all programs, and the connection between teaching in English and the achievement of international and intercultural learning outcomes is not clear. In other cases the focus of internationalization of the curriculum may be primarily on content through the inclusion of specialized optional international modules, and in others on increasing student diversity in the classroom and on campus, without considering how this will internationalize student learning. Individually and collectively these approaches are insufficient. In summary, internationalization of the curriculum in policy and practice is too often focused on inputs rather than outcomes. Internationalization of the curriculum must become more directly connected to all students' learning.

\section{Defining Internationalization of the Curriculum}

As there is often confusion about what the term internationalization of the curriculum actually means and how it is connected with student learning, I will first define the term and then describe two key characteristics of internationalization of the curriculum focused on student learning. In 2009, in an article in the Journal of Studies in International Education, I defined an internationalized curriculum as one that will "engage students with internationally informed research and cultural and linguistic diversity and purposefully develop their international and intercultural perspectives as global professionals and citizens."

This definition emphasizes the active involvement (engagement) of students in the learning process and through this the systematic (purposeful) development of international and intercultural learning outcomes. The definition highlights the need to move beyond approaches to internationalization of the curriculum based on content alone or isolated, optional experiences and activities for a few students that do not provide evidence of learning outcomes.

\section{The focus of internationalization of the curriculum in policy and practice is cur- rently more on what students will expe- rience than on what they will learn and how they will demonstrate their learn- ing.}

It is useful to distinguish between the product, an internationalized curriculum, as defined above, and the process of internationalization of the curriculum. The following definition of the process of internationalization of the curriculum from the same article focuses attention on teaching, learning, and assessment, as well as content: "internationalization of the curriculum is the incorporation of an international and intercultural dimension into the content of the curriculum as well as the teaching, learning, and assessment arrangements and support services of a program of study."

This distinction between product (an internationalized curriculum) and process (internationalization of the curriculum) helps to distinguish between the end and the means, an enduring source of confusion as evidenced by, for example, statements that claim mobility programs as evidence of internationalization of the curriculum. Mobility programs are a possible means by which a small number of students 
might achieve desired international and intercultural learning outcomes.

In summary, the process of internationalization of the curriculum must consider learning outcomes as well as learning inputs.

\section{An Internationalized Curriculum Focused on Student LEARNING}

An internationalized curriculum focused on student learning is defined by two key characteristics. First, it will occur within the context of the different cultures and practices of knowing, doing, and being in the disciplines. Second, faculty who do not have the experience, skills, or knowledge required to internationalize the curriculum will be supported by expert facilitators in the process of defining intended internationalized learning outcomes and assisting all students to achieve them.

\section{An internationalized curriculum will engage students with internationally informed research and cultural and lin- guistic diversity, and purposefully devel- op their international and intercultural perspectives as global professionals and citizens.}

Disciplines have distinct cultures and values and will often have different rationales for internationalizing the curriculum. Faculty will need to be clear about why they think internationalization of the curriculum is important for their program. Program teams, as distinct disciplinary communities, will need to engage in discussions and debates on the international and intercultural learning outcomes that their graduates will require to be effective professionals and citizens in a globalized world. If students are to achieve the intended learning outcomes faculty will need to develop a clear and systematic plan to support their students' learning. Learning activities in different modules/ subjects/courses at all year levels of the program will need to be designed to incrementally develop students' international perspectives and intercultural skills. Students will need formal and informal feedback on their international and intercultural learning and advice on how to improve their performance at different levels of the program.

Faculty who do not have the experience, skills, or knowledge required to internationalize the curriculum will need to be supported by expert facilitators in the process of defining intended internationalized learning outcomes and assisting all students to achieve them. Facilitation and support is important because faculty who are not prepared are likely to adopt a narrow focus. This will have serious consequences for the international strategy of the university and student learning.

Facilitators may come from outside the discipline or the university. They will include experts in teaching, learning, and internationalization, who can provide guidance and advice as well as practical support. There will be an emphasis on building capacity for the future to address critical issues and key questions associated with internationalization of the curriculum across disciplines and across the institution over time. In this way internationalization of the curriculum becomes an ongoing process focused on student learning, in which faculty are deeply engaged.

Approaches to and interpretations of internationalization of the curriculum will inevitably vary across disciplines. What is important is that, regardless of the discipline, the focus of the process of internationalizing the curriculum is focused on student learning. This puts faculty and the disciplines at the center of internationalization of the curriculum.

\section{Graduate Employability and Internationalization of the Curriculum at Home}

\section{ELSPETH JONES}

Elspeth Jones is Emerita Professor of the Internationalization of Higher Education at Leeds Metropolitan University, UK and Honorary Visiting Fellow at the Centre for Higher Education Internationalisation at the Università Cattolica del Sacro Cuore, Milan. E-mail: ej@elspethjones. com.

$\mathrm{O}$ ver the past two decades and more, frequent surveys of employers have found that, while graduates may have the technical skills required for a given role, they often lack the so-called soft skills that are key to effective working. Sometimes called employability skills, these include teamworking, negotiation, and mediation, problem-solving, and interpersonal skills, flexibility, organization, and good communication. These surveys have been conducted in a wide array of countries from Australia to Zambia, and similar 